OPEN ACCESS

Edited by:

Giorgio Treglia,

Ente Ospedaliero Cantonale

(EOC), Switzerland

Reviewed by:

Puja Panwar Hazari,

Institute of Nuclear Medicine \& Allied

Sciences (DRDO), India

Ismaheel Lawal,

University of Pretoria, South Africa

*Correspondence:

Ekaterina Dadachova

ekaterina.dadachova@usask.ca

Specialty section:

This article was submitted to

Nuclear Medicine,

a section of the journal

Frontiers in Medicine

Received: 22 November 2021

Accepted: 17 January 2022

Published: 11 February 2022

Citation:

Dadachova E and Rangel DEN (2022) Highlights of the Latest Developments in Radiopharmaceuticals for Infection Imaging and Future Perspectives.

Front. Med. 9:819702.

doi: 10.3389/fmed.2022.819702

\section{Highlights of the Latest Developments in Radiopharmaceuticals for Infection Imaging and Future Perspectives}

\author{
Ekaterina Dadachova $^{1 *}$ and Drauzio E. N. Range/ ${ }^{2}$ \\ ${ }^{1}$ College of Pharmacy and Nutrition, University of Saskatchewan, Saskatoon, SK, Canada, ${ }^{2}$ Universidade Brazil, São Paulo, \\ Brazil
}

COVID-19 pandemic has heightened the interest toward diagnosis and treatment of infectious diseases. Nuclear medicine with its powerful scintigraphic, single photon emission computer tomography (SPECT) and positron emission tomography (PET) imaging modalities has always played an important role in diagnosis of infections and distinguishing them from the sterile inflammation. In addition to the clinically available radiopharmaceuticals there has been a decades-long effort to develop more specific imaging agents with some examples being radiolabeled antibiotics and antimicrobial peptides for bacterial imaging, radiolabeled anti-fungals for fungal infections imaging, radiolabeled pathogen-specific antibodies and molecular engineered constructs. In this opinion piece, we would like to discuss some examples of the work published in the last decade on developing nuclear imaging agents for bacterial, fungal, and viral infections in order to generate more interest among nuclear medicine community toward conducting clinical trials of these novel probes, as well as toward developing novel radiotracers for imaging infections.

Keywords: infection imaging, antibiotics, anti-fungals, antimicrobial peptides, antibodies, HIV, PET, SPECT

\section{INTRODUCTION}

COVID-19 pandemic has heightened the interest toward diagnosis and treatment of infectious diseases. Nuclear medicine with its powerful scintigraphic, single photon emission computer tomography (SPECT) and positron emission tomography (PET) imaging modalities has always played an important role in diagnosis of infections and distinguishing them from the sterile inflammation. The classical tools developed decades ago but still widely used in the clinic today are ${ }^{111}$ In-labeled leukocyte imaging for most indications, ${ }^{67} \mathrm{Ga}$ for imaging of opportunistic infections, pulmonary inflammation and interstitial nephritis and 2-Deoxy-2- $\left[{ }^{18} \mathrm{~F}\right]$ fluoroglucose $\left(\left[{ }^{18} \mathrm{~F}\right] \mathrm{FDG}\right)$ for spinal osteomyelitis, vasculitis, sarcoidosis, and fever of unknown origin $(1,2)$ as well as for identifying cardiovascular device infection (3).

In addition to these clinically available radiopharmaceuticals there has been a decadeslong effort to develop more specific imaging agents with some examples being radiolabeled antibiotics and antimicrobial peptides for bacterial imaging, radiolabeled anti-fungals for fungal infections imaging, radiolabeled pathogen-specific antibodies and molecular 
engineered constructs. Several excellent reviews on these agents which are primarily still in the preclinical stage have appeared in the last decade (4-6). In this opinion piece, we would like to discuss some examples of the work published in the last decade on developing nuclear imaging agents for bacterial, fungal and viral infections in order to generate more interest among nuclear medicine community toward conducting clinical trials of these novel probes, as well as toward developing novel radiotracers for imaging infections.

\section{IMAGING BACTERIAL INFECTIONS WITH RADIOLABELED ANTIBIOTICS, SUGARS, ANTIBACTERIAL PEPTIDES AND BACTERIAL ANTIGEN-SPECIFIC ANTIBODIES}

Imaging of bacterial infections is by far the most developed area of infection imaging. Multiple antibiotics with a variety of mechanisms of action such as ciproflaxicin $(7,8)$ and nitrofuryl thiosemicarbazone (7), fluoroquinolone (9), isoniazid (10), ofloxacin $(11,12)$, cephalosporin (13), clindamycin (14), doxycycline (15), ceftizoxime $(16,17)$, cefotaxime (18), tinidazole (19), sulfadiazine (20), tazobactam (21) and metronidazole (22) were radiolabeled with ${ }^{99} \mathrm{~m}$ Tc to enable SPECT imaging in the pre-clinical models of infection. The majority of the authors employed $\operatorname{Sn}(+2)$ salts as the reducing agents for ${ }^{99 \mathrm{~m}} \mathrm{Tc}$ which produced $\left[{ }^{99 \mathrm{~m}} \mathrm{Tc}-\mathrm{O}\right](3+)$ core, while in several publications ${ }^{99 \mathrm{~m}} \mathrm{Tc}$ carbonyl or $\left[{ }^{99 \mathrm{~m}} \mathrm{Tc}-\mathrm{N}\right](2+)$ cores were utilized $(7,8,11)$. The smaller size of ${ }^{99 \mathrm{~m}} \mathrm{Tc}$ carbonyl core might be less perturbing to the molecular structure of antibiotic molecules. Satpati et al. used a smaller sized radiometal, PET enabling ${ }^{68} \mathrm{Ga}$, for labeling of ciprofloxacin via two common bifunctional chelating agents $2,2^{\prime}, 2^{\prime \prime}, 2^{\prime \prime \prime}-(1,4,7,10-$ Tetraazacyclododecane-1,4,7,10-tetrayl)tetraacetic acid (DOTA) and 2,2',2' -(1,4,7-triazacyclononane-1,4,7-triyl)triacetic acid (NOTA) (23). However, both of these chelating agents are quite bulky macrocycles. In this regard, Northrup et al. (24) considered labeling antibiotics with radiometals problematic as it can affect the probe entering the bacterium, or interfere with the binding to the intracellular target.

To avoid radiometals, one can potentially use PET-enabling "organic" radionuclides such as ${ }^{13} \mathrm{~N}$ or ${ }^{11} \mathrm{C}$, or ${ }^{18} \mathrm{~F}$ as proposed by Naqvi and Drlica (25) which should not perturb the molecular structure of an antibiotic due to the latter small atomic radius. Wang et al. labeled PT119, a potent Staphylococcus aureus enoylACP reductase (saFabI) inhibitor, with ${ }^{11} \mathrm{C}$ and performed PET imaging of $S$. aureus-infected mice with this agent (26). Mota et al. performed PET imaging of ${ }^{18} \mathrm{~F}$-linezolid in a mouse model of pulmonary tuberculosis (TB) (27). Liu et al. took the use of "organic" radionuclides one step further by radiolabeling antiTB chemotherapeutics isoniazid (INH), rifampicin (RIF), and pyrazinamide (PZA) with ${ }^{11} \mathrm{C}$ and performing the whole body PET imaging of each radiolabeled drug in baboons (28). They also used the polyethylene glycol (PEG)ylated forms of the same anti-TB drugs for PET imaging and made a conclusion about the potential utility of the PEGylated isoniazid conjugates as long-circulating carriers for improved therapy of TB (28). Of course, when choosing a radionuclide for antibiotics labeling, researchers have to take into consideration the radionuclide cost, its availability and accessibility of the SPECT or PET imaging equipment in their institutions.

The majority of the infection models used in the preclinical studies of radiolabeled antibiotics were murine, but some groups used rabbits $(10,14,19,20)$, as the immune system of rabbits is considered to be closer to a human immune system (29). Staphylococcus aureus was used most often to induce infection in experimental animals, but other bacteria such as Mycobaterium tuberculosis (10), Bacteroides fragilis and Dentamoeba fragilis (19), E. coli (20,22), Pseudomonas aeruginosa and Salmonella enterica (21) which are also important from the clinical perspective were utilized as well. Many groups not only imaged the localization of the radiolabeled antibiotics with SPECT or PET but also quantified the images and in some case performed the biodistribution in addition to imaging. Kakkar et al. reported retention of ${ }^{99 \mathrm{~m}}$ Tc-labeled isoniazid at the sites of $M$. tuberculosis infection in rabbits for $72 \mathrm{~h}(10)$.

In $S$. aureus mouse model the biodistribution results showed that accumulation of ${ }^{99 \mathrm{~m}} \mathrm{Tc}$-ofloxacin in the infected muscle reached target to non-target (T/NT) ratio of 2 at $4 \mathrm{~h}$ post injection (11) while ${ }^{68} \mathrm{Ga}$-ciprofloxacin tested in rats infected with $S$. aureus demonstrated T/NT ratio of 3-6 at $2 \mathrm{~h}$ depending on the chelating agent used (23). In E. coli rabbit model the accumulation of ${ }^{99 \mathrm{~m}} \mathrm{Tc}$-metronidazole at $1 \mathrm{~h}$ post injection reached T/NT ratio of 5.57 (22). Interestingly, the authors of all reviewed here manuscripts concluded that their results were encouraging. It is not clear at the moment what stands in a way of clinical translation of these relatively cheap radiopharmaceuticals. It might be the single digit values for absolute uptake in the infected sites which is lower than usually reported numbers for tumor uptake in the preclinical studies. However, in human patients the situation might be different and first in man clinical trials of radiolabeled antibiotics seem to be warranted.

Antimicrobial peptides (AMPs), described as natural microbicides, accumulate at the sites of the bacterial infection due to their positive charge which is electrostatically attracted to the negative charged surface of the bacterial cells. This feature makes them attractive as potential infection imaging agents (30). Among multiple AMPs ubiquicidin (UBI) seems to be one of the most widely used in the preclinical work and in clinical trials. It has been labeled with ${ }^{99 \mathrm{~m}}$ Tc via hydrazinonicotinamide (HYNIC) or other chelating agents to enable SPECT imaging $(31,32)$ but relatively recent availability of PET-enabling ${ }^{68} \mathrm{Ga}$ has made the labeling with the latter supplanting other radionuclides due to the good match between short physical half-life of ${ }^{68} \mathrm{Ga}(68 \mathrm{~min})$ and short plasma half-life of ubiquicidin and other AMPs $(33,34)$. Other recently described AMPs-radionuclide combinations include [99m Tc-HYNIC/EDDA]-MccJ25 (35); $99 \mathrm{~m}$ Tc-human beta-defensin 3 (HBD-3) (36); ${ }^{64} \mathrm{Cu}$-labeled cationic peptides HLys-DOTA, synthesized as the D-isomer and AB1-HLysDOTA, synthesized with an unnatural aminoacid to slow down the blood clearance (37); and ${ }^{68}$ Ga-DOTA-CF-17 (38). 
The advantage of AMPs over radiolabeled antibiotics is that AMP are larger molecules which should allow attachment of radiolabels without loss of the ability to bind bacteria in a specific manner; the disadvantage is their fast blood clearance due to enzymatic destruction and also high kidney uptake. Evaluation of AMPs in murine models of $S$. aureus $(34,36-38)$, mice with $E$. coli infection (35), $P$. aeruginosa (38) demonstrated the highest target to non-target ratios of 2-6 reached from 45 to 120 min post administration of radiolabeled peptides, showing their ability to distinguish the infected tissues from sterile inflammation. Auletta et al. performed side by side comparison of ${ }^{99 \mathrm{~m}} \mathrm{Tc}$ Ubiquicidin 29-41, ${ }^{99} \mathrm{~m}$ Tc-ciprofloxacin and ${ }^{99} \mathrm{~m}$ Tc-ciprofloxacin dithiocarbamate (CS2) in vitro and in mice with $S$. aureus and E.coli infections (32). They concluded that ${ }^{99 \mathrm{~m}} \mathrm{Tc}-\mathrm{UBI}$ and ${ }^{99} \mathrm{~m}$ TcN-Cipro CS2 showed good in vivo binding to E. coli only while ${ }^{99 \mathrm{~m}} \mathrm{Tc}$-Ciprofloxacin demonstrated good in vivo binding to both E. coli and S. aureus.

The radiolabeled antimicrobial peptides have been tested in first in man type of clinical trials. Kamaleshwaran reported the diagnosis of knee prosthesis infection with ${ }^{99 \mathrm{~m}}$ Tc-ubiquicidin scintigraphy and its comparison with FDG PET/CT (31). Both of the traces were able to diagnose the infection. Ebenhan et al. evaluated ${ }^{68} \mathrm{Ga}-\mathrm{NOTA}-\mathrm{UBI}$ with PET/CT in two healthy volunteers and 3 patients with suspected bacterial infection (32). ${ }^{68} \mathrm{Ga}$-NOTA-UBI was able to diagnose bone- and soft-tissue infection in all three patients. Radiation dosimetry performed as part of this trial identified bladder wall as a dose-limiting tissue (185 $\mu \mathrm{Sv} / \mathrm{MBq})$, followed by the kidneys ( $23 \mu \mathrm{Sv} / \mathrm{MBq})$. The total absorbed body dose was below $7 \mu \mathrm{Sv} / \mathrm{MBq}$ with the effective dose being $\sim 17 \mu \mathrm{Sv} / \mathrm{MBq}$. The authors concluded that ${ }^{68} \mathrm{Ga}$-NOTAUBI is a promising diagnostic technique for infection imaging.

The problem of distinguishing between a sterile inflammation and a bacterial infection is important, especially in postoperative patients. It prompted the studies of imaging molecules which would target bacteria-specific metabolic pathways. Recent studies from several groups have demonstrated that it is possible to radiolabel with ${ }^{18} \mathrm{~F}$ sugars and sugar alcohols that are not efficiently metabolized by humans, such as 2-deoxy$2-\left[{ }^{18} \mathrm{~F}\right]$ fluorosorbitol ( $\left.{ }^{18} \mathrm{~F}-\mathrm{FDS}\right), 6-\left[{ }^{18} \mathrm{~F}\right]$ fluoromaltose, and $6{ }^{\prime \prime}$ $\left[{ }^{18} \mathrm{~F}\right]$ fluoromaltotriose without interfering with their uptake by bacteria thus creating the probes for PET imaging (39-41). The approach of radiolabeling sugars in the SPECT arena has also been pursued-Shukla et al. radiolabeled hydroxypropyl- $\beta$ cyclodextrin (HP $\beta C D$ ), a oligosaccharide derivative, with ${ }^{99 \mathrm{~m}} \mathrm{Tc}$ to assist with the differentiation between loosening of prosthesis due to septic or aseptic course in patients (42). Nanoparticles ${ }^{99 \mathrm{~m}} \mathrm{Tc} \mathrm{HP} \beta \mathrm{CD}$ in the quantity of $0.5-1.0 \mathrm{mg}$ were injected in human subjects with clinically confirmed infected knee joints, with clear distinction between the septic and aseptic loosening being observed on SPECT images (42), thus providing first in man clinical experience with radiolabeled sugars for bacterial infection imaging.

Some interesting insights into imaging of bacterial infections with the radiolabeled antibodies have been reported recently. Pickett et al. evaluated a human monoclonal antibody (mAb) which binds to the Gram-positive bacterial surface molecule lipoteichoic acid (LTA) by radiolabeling this anti-LTA $\mathrm{mAb}$
SAC55 with ${ }^{89} \mathrm{Zr}$ and investigating its utility as a PET agent for diagnosis of infection in a mouse model of prosthetic joint infection (PJI) (43). Twenty four hours post-injection ${ }^{89} \mathrm{Zr}$ SAC55 displayed significantly higher uptake at $S$. aureus-infected prosthesis sites than at the sterile prosthesis sites. Importantly, ${ }^{89} \mathrm{Zr}$-SAC55 uptake at the infected site was also higher than that of the control non-specific antibody, thus demonstrating specificity and selectivity. Foss et al. pursued the imaging of $M$. tuberculosis bacteria whose mostly intracellular location makes it difficult to detect it with the antibodies (44). The strategy used by the authors was to develop an antibody (mAb 3d29) which recognizes the tissue-bound terminal processing fragments $\mathrm{iC} 3 \mathrm{~b}$ and $\mathrm{C} 3 \mathrm{~d}$ of $\mathrm{C} 3$ complement but not the native circulating C3 or tissue-bound C3b. SPECT with ${ }^{125} \mathrm{I}-3 \mathrm{~d} 29$ mAb showed lesions in the lungs and spleens of the aerosol-infected with $M$. tuberculosis $\mathrm{C} 3 \mathrm{HeB} / \mathrm{FeJ}$ mice at 24 and $48 \mathrm{~h}$ post-administration. These lesions colocalized with granulomas detected by CT, and the antibody was detected in the cytoplasm of macrophages, and within alveolar epithelial cells which is consistent with the location of internalized $M$. tuberculosis. Very insignificant uptake of the ${ }^{125} \mathrm{I}-3 \mathrm{~d} 29 \mathrm{mAb}$ in the lungs and spleen of the healthy mice and 3.5:1 ratio of increased uptake of ${ }^{125} \mathrm{I}-3 \mathrm{~d} 29 \mathrm{mAb}$ over isotype control $\mathrm{mAb}$ in infected lungs allowed the authors to conclude that ${ }^{125} \mathrm{I}-3 \mathrm{~d} 29$ can be utilized for localization of $M$. tuberculosis infection $24 \mathrm{~h}$ after administration.

\section{IMAGING OF FUNGAL INFECTIONS WITH RADIOLABELED ANTI-FUNGAL DRUGS AND ANTIBODIES}

Invasive fungal infections especially in immunocompromised patients are on the rise worldwide and there is a need to diagnose them in an expedited manner as the growth of fungal cultures obtained from patients might take weeks which is often not feasible for critically ill patients (45). Page et al. aimed at developing cost-efficient and broadly useful tracers for pulmonary mold infections by radiolabeling amphotericin $\mathrm{B}$ (AMB) with ${ }^{99 \mathrm{~m}} \mathrm{Tc}$ and ${ }^{68} \mathrm{Ga}$. The radiolabeled antifungal was stable in human serum and both tracers accumulated specifically in Transwell inserts infected with Aspergillus fumigatus, Rhizopus arrhizus, and other clinically relevant mold pathogens in comparison with uninfected inserts or inserts infected with bacterial controls (46). This encouraging in vitro study warrants further in vivo evaluation of radiolabeled amphotericin B for molecular imaging of invasive mycoses.

Fungi capable of human pathogenesis have developed special siderophore metabolism as a way to pirate the iron in the challenging iron-free environment of a host. Siderophore metabolism of $A$. fumigatus was investigated by Petrik et al. and Haas et al. by making $\mathrm{N}^{2}$-acetylated derivative triacetylfusarinine $\mathrm{C}\left({ }^{68} \mathrm{Ga}\right.$-TAFC) and ${ }^{68} \mathrm{Ga}$-ferrioxamine E ( ${ }^{68} \mathrm{Ga}$-FOXE) PETenabling molecules $(47,48)$. These probes showed fast uptake in the lungs of A. fumigatus-infected rats, low accumulation in sterile inflammation and no uptake in bacterial abscess $(47,48)$. The drawback of this approach is the absence of siderophore 
metabolism in several clinically relevant fungi, which will require to first diagnose the fungal infection by a different technique.

Other groups pursued the imaging approach based on fungal antigen-specific antibodies. Davies et al. developed a humanized mAb hJF5 binds to the antigenic determinant $\beta 1,5$ galactofuranose $(\mathrm{Gal} f)$ present in a diagnostic mannoprotein antigen released by the pathogen during invasive growth in the lung while this epitope Galf is absent in mammalian carbohydrates (49). The authors performed PET imaging of $A$. fumigatus lung infection in mice with $\left[{ }^{64} \mathrm{Cu}\right]$ NODAGA-hJF5 $\mathrm{mAb}$. In vivo quantification demonstrated higher uptake of $\left[{ }^{64} \mathrm{Cu}\right]$ NODAGA-hJF5 $\mathrm{mAb}$ in the lungs of infected mice in comparison with the PBS-treated controls or with infected and control animals administered with free radionuclude $\left[{ }^{64} \mathrm{Cu}\right] \mathrm{Cl}_{2}$. In this regard, uptake of $\left[{ }^{64} \mathrm{Cu}\right]$ NODAGA-hJF5 in the lungs of infected mice $48 \mathrm{~h}$ post administration was $17.1 \pm 2.5 \% \mathrm{ID} / \mathrm{cc}$ while that in PBS-treated control mice was $9.4 \pm 1.1 \% \mathrm{ID} / \mathrm{cc}$. Henneberg et al. continued development of hJF5 as an imaging agent not only for detection of A. fumigatus infections but also for monitoring the response to azole treatment (50). For this purpose they dual labeled hJF5 with ${ }^{64} \mathrm{Cu}$ and fluorophore and performed immunoPET/MRI in vivo in a neutropenic mouse model of A. fumigatus infection. They concluded that antibodyguided approach revealed that early drug intervention is critical to prevent complete invasion of the lungs by the pathogen, and showed the potential of immunoPET for diagnosis and monitoring A. fumigatus infections.

\section{IMAGING OF VIRAL INFECTIONS}

Viral infections with human immunodeficiency virus (HIV), influenza A and SARS-CoV-2 result in deadly acute disease such as AIDS, influenza and COVID-19, respectively, while some viral infections such as human papilloma virus HPV-16 and HPV-18 viruses are a causation behind several types of cancer, e.g., cervical, anal, and head and neck cancers. In this regard, nuclear imaging can be indispensable for non-invasive detection of virally infected cells, monitoring the treatment progression or side effects.

Immune system can recognize peptides on major histocompatibility molecules which helps to the eradicate infectious agents and even cancers. In vivo imaging of such responses could assist with evaluating the efficacy of immune interventions. and improve mechanistic understanding of immune responses. Woodham et al. utilized synTacs, which are dimeric major histocompatibility molecule scaffolds of defined composition, for imaging antigen-specific CD8(+) $\mathrm{T}$ cells in vivo (51). The authors imaged HPV16 E7-specific CD8 T cells with PAT by utilizing a ${ }^{89} \mathrm{Zr}$ - or ${ }^{64} \mathrm{Cu}$-labeled HPV16 E7 peptide-loaded synTac in HPV16-positive tumors, following administration of a therapeutic vaccine. ImmunoPET with flu-specific synTac also produced positive results in imaging of influenza A virus (IAV) nucleoprotein-specific CD8 T cells in the lungs of IAV-infected mice. The authors have concluded that it is possible to visualize antigen-specific CD8 $+\mathrm{T}$ cell populations in $v i v o$, which may play prognostic and diagnostic roles.
Some of the most pressing questions in HIV researchrevealing viral dissemination in real-time and detecting HIV reservoirs during suppressive antiretroviral therapy (ART) remain a challenge and are currently limited to blood sampling and biopsies. There is an enduring assumption in HIV field which, however, to the best of our knowledge is not based on any experimental data, that during ART virally infected cells do not express any HIV-specific antigens on their surface and thus, cannot be imaged in vivo. Song et al. genetically engineered simian immunodeficiency virus (SIV) to carry different imaging reporters with the purpose of demonstrating that in vivo imaging can be used to visualize SIV-transduced cells (52). Based on the expression of the reporter genes, the group was able to image and enumerate the SIV-transduced cells via vesicular stomatitis virus glycoprotein pseudotyping in a mouse model using bioluminescence imaging, PET-CT or MRI. In addition, they also engineered a chimeric EcoSIV for in vivo infection study and were able to prove that PET-CT can provide 3D images of the spatial location of as few as 10,000 SIV-infected cells. Santagelo et al. extended imaging of SIV reservoirs to nonhuman primate model (NHP) (53). The authors administrated that a radiolabeled with ${ }^{64} \mathrm{Cu}$ pegylated SIV Gp120-specific mAb produced readily detectable signals during PET/CT imaging in the gastrointestinal and respiratory tract, lymphoid tissues and reproductive organs of viremic monkeys. These viral signals were reduced in aviremic NHPs but still detectable in colon, select lymph nodes, small bowel, nasal turbinates, the genital tract and lung, thus invalidating the assumption that virally infected cells cannot be imaged in patients on ART. Moreover, in elite controllers, virus was detected primarily in foci in the small bowel, select lymphoid areas and the male reproductive tract, as confirmed by quantitative reverse-transcription PCR (qRT-PCR) and immunohistochemistry. The authors concluded that immunoPET viral imaging has broad applications for the study of immunodeficiency virus pathogenesis, drug and vaccine development, and the potential for clinical translation. The presence of HIV gp41 protein on the surface of cells from HIV patients on different ART regimens was subsequently demonstrated ex vivo with radiolabeled mAbs to human HIV gp41 (54).

The urgency of imaging patients acutely ill with COVID-19 as well as following up post-COVID patients and those receiving vaccines, did not allow for time to create SARS-CoV-2 specific imaging agents. The domineering modality so far has been FDGPET/CT covered in several excellent reviews $(55,56)$ while SPECT imaging also contributes, for example, toward imaging of pulmonary emboli in COVID patients (57). As COVID-19 will gradually become endemic, it is only a matter of time when COVID-specific PET and SPECT imaging agents are developed.

\section{FUTURE PERSPECTIVES}

\section{Problems Preventing Clinical Translation of Infection Imaging Agents}

The field of infections imaging is still far behind oncology or neurology in investigating novel tracers in clinical trials (58). This 
is in spite of the rich armamentarium of novel tracers for imaging of bacterial, fungal and viral infections which preclinical research has already generated. One of the problems facing researchers who would like to translate their findings into the clinic, is the lack of the standardized infection models, which makes it difficult to compare the results generated by various research groups and to accumulate the preclinical data needed for regulatory submissions leading to a clinical trial. Many microbiologists and infectious disease physicians are unaware of the existence of the wide range of imaging agents and because of this do not use them in their research practice and do not initiate clinical trials. Finally, radiopharmaceutical companies whose funding is essential for crossing the "death valley" between the laboratory research and clinical investigation have not invested so far any significant funds and effort in bringing novel infection imaging agents into the clinic.

\section{Possible Ways Forward}

Informative meetings of research and medical community with regulatory agencies such as the United States Food and Drug Administration (FDA) to provide the guidance on the preferred animal models of infections and the scope of preclinical work required for filing an Investigational New Drug (IND) application for a new infection imaging agent would greatly assist in moving novel infection imaging agents toward the clinic. In this regard, FDA and Nuclear Research Council (NRC) have recently conducted a series of joint webinars on alpha-emitter radio-therapeutic agents and the same format could be used for the infection imaging agents. There is also

\section{REFERENCES}

1. Palestro CJ, Glaudemans A, Dierckx R. Multiagent imaging of inflammation and infection with radionuclides. Clin Transl Imaging. (2013) 1:38596. doi: 10.1007/s40336-013-0041-z

2. Palestro CJ. Radionuclide imaging of osteomyelitis. Semin Nucl Med. (2015) 45:32-46. doi: 10.1053/j.semnuclmed.2014.07.005

3. Chen W, Dilsizian V. Molecular imaging of cardiovascular device infection: targeting the bacteria or the host-pathogen immune response? J Nucl Med. (2020) 61:319-26. doi: 10.2967/jnumed.119.228304

4. Sasser TA, Van Avermaete AE, White A, Chapman S, Johnson JR, Van Avermaete T, et al. Bacterial infection probes and imaging strategies in clinical nuclear medicine and preclinical molecular imaging. Curr Top Med Chem. (2013) 13:479-87. doi: 10.2174/1568026611313040008

5. Ebenhan T, Lazzeri E, Gheysens O. Imaging of bacteria: Is there any Hope for the future based on past experience? Curr Pharm Des. (2018) 24:77286. doi: 10.2174/1381612823666171122111558

6. Naqvi SAR. (99m) Tc-labeled antibiotics for infection diagnosis: mechanism, action, and progress. Chem Biol Drug Des. (2021) 2022:965238. doi: 10.1111/cbdd.13923

7. Halder KK, Nayak DK, Baishya R, Sarkar BR, Sinha S, Ganguly S, et al. $(99 \mathrm{~m}) \mathrm{Tc}$-labeling of ciprofloxacin and nitrofuryl thiosemicarbazone using fac$[(99 \mathrm{~m}) \mathrm{Tc}(\mathrm{CO}) 3(\mathrm{H} 2 \mathrm{O}) 3]$ core: evaluation of their efficacy as infection imaging agents. Metallomics. (2011) 3:1041-8. doi: 10.1039/c1mt00068c

8. Fang S, Jiang Y, Gan Q, Ruan Q, Xiao D, Zhang J. Design, preparation, and evaluation of a novel $(99 \mathrm{~m}) \mathrm{TcN}$ complex of ciprofloxacin xanthate as a potential bacterial infection imaging agent. Molecules. (2020) 25:5837. doi: 10.3390/molecules25245837

9. Zhang S, Zhang W, Wang Y, Jin Z, Wang X, Zhang J, et al. Synthesis and biodistribution of a novel $((9)(9) \mathrm{m}) \mathrm{TcN}$ complex of norfloxacin a need for the radiopharmaceutical scientists developing new infection imaging agents to establish connections with the infectious disease physicians and to inform them about the new agents and opportunities for collaborative research and clinical trials. Ongoing COVID-19 pandemic has demonstrated to the biotechnology and pharmaceutical industries that there are ample business opportunities in the infectious diseases arena including patients diagnostic imaging. In addition, total body PET/CT greatly assists in new drug development by providing an opportunity to study the biokinetics of the radiolabeled forms of the drugs in all infectious foci in the body at the same time. Thus, we hope that current resurgent interest toward imaging of infections will provide the final push for concerted effort toward clinical testing of multiple promising infection imaging agents.

\section{AUTHOR CONTRIBUTIONS}

ED and DR performed the literature search. ED analyzed the data and wrote the first draft of the manuscript. All authors contributed to the article and approved the submitted version.

\section{FUNDING}

The research was partially funded by the Fedoruk Center for Nuclear Innovation. We also thank the National Council for Scientific and Technological Development (CNPq) of Brazil PQ1D302100/2018-0 to DR and to São Paulo Research Foundation (FAPESP) 2010/06374-1 to DR. dithiocarbamate as a potential agent for bacterial infection imaging. Bioconjug Chem. (2011) 22:369-75. doi: 10.1021/bc100357w

10. Kakkar D, Tiwari AK, Chuttani K, Khanna A, Datta A, Singh H, et al. Design, synthesis, and antimycobacterial property of PEG-bis(INH) conjugates. Chem Biol Drug Des. (2012) 80:245-53. doi: 10.1111/j.1747-0285.2012.01394.x

11. Erfani M, Doroudi A, Hadisi L, Andishmand A, Mirshojaei SF, Shafiei M. (99m) Tc-tricabonyl labeling of ofloxacin and its biological evaluation in Staphylococcus aureus as an infection imaging agent. J Labelled Comp Radiopharm. (2013) 56:627-31. doi: 10.1002/jlcr.3093

12. Mukherjee A, Sahoo S, Sarma HD, Chakraborti CK, Samuel G. Preparation and evaluation of three mucoadhesive dosage forms using (99m)Tc-Ofloxacin. Appl Radiat Isot. (2014) 89:192-8. doi: 10.1016/j.apradiso.2014.01.031

13. Kaul A, Hazari PP, Rawat H, Singh B, Kalawat TC, Sharma S, et al. Preliminary evaluation of technetium-99m-labeled ceftriaxone: infection imaging agent for the clinical diagnosis of orthopedic infection. Int J Infect Dis. (2013) 17:e263-270. doi: 10.1016/j.ijid.2012.10.011

14. Hina S, Rajoka MI, Roohi S, Haque A, Qasim M. Preparation, biodistribution, and scintigraphic evaluation of (99m)Tc-clindamycin: an infection imaging agent. Appl Biochem Biotechnol. (2014) 174:1420-33. doi: 10.1007/s12010-014-1075-z

15. Ilem-Ozdemir D, Asikoglu M, Ozkilic H, Yilmaz F, Hosgor-Limoncu M, Ayhan S. (99m) Tc-Doxycycline hyclate: a new radiolabeled antibiotic for bacterial infection imaging. J Labelled Comp Radiopharm. (2014) 57:3641. doi: $10.1002 /$ jlcr.3135

16. Ferreira Ddos S, Boratto FA, Cardoso VN, Serakides R, Fernandes SO, Ferreira LA, et al. Alendronate-coated long-circulating liposomes containing 99mtechnetium-ceftizoxime used to identify osteomyelitis. Int J Nanomed. (2015) 10:2441-50. doi: 10.2147/IJN.S76168

17. Teixeira LE, Soares GG, Teixeira HC, Takenaka IK, Diniz SO, de Andrade MA, et al. Efficacy of $(99 \mathrm{~m}) \mathrm{Tc}$-labeled ceftizoxime in the diagnosis of subclinical 
infections associated with titanium implants in rats. Surg Infect. (2015) 16:352-7. doi: 10.1089/sur.2014.186

18. Ilem-Ozdemir D, Asikoglu M, Ozkilic H, Yilmaz F, Hosgor-Limoncu M, Ayhan S. Gamma scintigraphy and biodistribution of (99m)Tc-cefotaxime sodium in preclinical models of bacterial infection and sterile inflammation. $J$ Labelled Comp Radiopharm. (2016) 59:109-16. doi: 10.1002/jlcr.3374

19. Sharma BG, Kumar N, Nishad DK, Khare NK, Bhatnagar A. Development of microbial trigger based oral formulation of Tinidazole and its gamma scintigraphy evaluation: a promising tool against anaerobic microbes associated GI problems. Eur J Pharm Sci. (2016) 89:94-104. doi: 10.1016/j.ejps.2016.04.022

20. Ahmed MT, Naqvi SAR, Rasheed R, Zahoor AF, Usman M, Hussain Z. Technetium-99m-labeled sulfadiazine: a targeting radiopharmaceutical for scintigraphic imaging of infectious foci due to Escherichia coli in mouse and rabbit models. Appl Biochem Biotechnol. (2017) 183:37484. doi: 10.1007/s12010-017-2451-2

21. Rasheed R, Naqvi SAR, Gillani SJH, Zahoor AF, Jielani A, Saeed N. (99m) Tctazobactam, a novel infection imaging agent: radiosynthesis, quality control, biodistribution, and infection imaging studies. J Labelled Comp Radiopharm. (2017) 60:242-9. doi: 10.1002/jlcr.3494

22. Iqbal A, Naqvi SAR, Rasheed R, Mansha A, Ahmad M, Zahoor AF. Radiosynthesis and biodistribution of $(99 \mathrm{~m}) \mathrm{Tc}-$ Metronidazole as an Escherichia coli infection imaging radiopharmaceutical. Appl Biochem Biotechnol. (2018) 185:127-39. doi: 10.1007/s12010-017-2641-y

23. Satpati D, Arjun C, Krishnamohan R, Samuel G, Banerjee S. (68) Ga-labeled ciprofloxacin conjugates as radiotracers for targeting bacterial infection. Chem Biol Drug Des. (2016) 87:680-6. doi: 10.1111/cbdd.12701

24. Northrup JD, Mach RH, Sellmyer MA. Radiochemical approaches to imaging bacterial infections: Intracellular versus extracellular targets. Int J Mol Sci. (2019) 20:5808. doi: 10.3390/ijms20225808

25. Naqvi SAR, Drlica K. Fluoroquinolones as imaging agents for bacterial infection. Dalton Trans. (2017) 46:14452-60. doi: 10.1039/C7DT01189J

26. Wang $\mathrm{H}, \mathrm{Lu}$ Y, Liu L, Kim SW, Hooker JM, Fowler JS, et al. Radiosynthesis and biological evaluation of a novel enoyl-ACP reductase inhibitor for Staphylococcus aureus. Eur J Med Chem. (2014) 88:6673. doi: 10.1016/j.ejmech.2014.09.008

27. Mota F, Jadhav R, Ruiz-Bedoya CA, Ordonez AA, Klunk MH, Freundlich JS, et al. Radiosynthesis and biodistribution of (18)F-Linezolid in Mycobacterium tuberculosis-infected mice using positron emission tomography. ACS Infect Dis. (2020) 6:916-21. doi: 10.1021/acsinfecdis.9b00473

28. Liu L, Xu Y, Shea C, Fowler JS, Hooker JM, Tonge PJ. Radiosynthesis and bioimaging of the tuberculosis chemotherapeutics isoniazid, rifampicin and pyrazinamide in baboons, J Med Chem. (2010) 53:2882-91. doi: 10.1021/jm901858n

29. Esteves PJ, Abrantes J, Baldauf HM, BenMohamed L, Chen Y, Christensen N, et al. The wide utility of rabbits as models of human diseases. Exp Mol Med. (2018) 50:1-10. doi: 10.1038/s12276-018-0094-1

30. Ebenhan T, Gheysens O, Kruger HG, Zeevaart JR, Sathekge MM. Antimicrobial peptides: their role as infection-selective tracers for molecular imaging. Biomed Res Int. (2014) 2014:867381. doi: 10.1155/2014/867381

31. Kamaleshwaran KK, Rajkumar N, Mohanan V, Kalarikal R, Shinto AS. 99m-Tc-ubiquicidin scintigraphy in diagnosis of knee prosthesis infection and comparison with F-18 fluorodeoxy-glucose positron emission tomography/computed tomography. Indian J Nucl Med. (2015) 30:25962. doi: $10.4103 / 0972-3919.158540$

32. Auletta, S., Baldoni D, Varani M, Galli F, Hajar IA, Duatti A, et al. Comparison of 99mTc-UBI 29-41, 99mTc-ciprofloxacin, 99mTc-ciprofloxacin dithiocarbamate and 111In-biotin for targeting experimental Staphylococcus aureus and Escherichia coli foreign-body infections: an ex-vivo study. Q J Nucl Med Mol Imaging. (2019) 63:37-47. doi: 10.23736/S1824-4785.17.02975-2

33. Ebenhan T, Sathekge MM, Lengana T, Koole M, Gheysens O, Govender T. et al. (68)Ga-NOTA-functionalized ubiquicidin: cytotoxicity, biodistribution, radiation dosimetry, and first-in-human PET/CT imaging of infections. J Nucl Med. (2018) 59:334-9. doi: 10.2967/jnumed.117.200048

34. Boddeti DK, Kumar V. Evaluation of (68)Ga-DOTA-Ubiquicidin (29-41) for imaging Staphylococcus aureus (Staph A) infection and turpentine-induced inflammation in a preclinical setting. World J Nucl Med. (2021) 20:26672. doi: 10.4103/wjnm.WJNM_103_20
35. Mazaheri Tehrani M, Erfani M, Amirmozafari N. [(99m) Tc-HYNIC/EDDA]MccJ25 antimicrobial peptide analog as a potential radiotracer for detection of infection. Chem Biol Drug Des. (2021) 97:904-13. doi: 10.1111/cbdd.13817

36. Follacchio GA, Pala A, Scaccianoce S, Monteleone F, Colletti PM, Rubello $\mathrm{D}$, et al. In vivo microbial targeting of $99 \mathrm{mTc}$-labeled human betaDefensin-3 in a rat model of infection. Clin Nucl Med. (2019) 44:e6026. doi: 10.1097/RLU.0000000000002713

37. Aweda TA, Muftuler ZFB, Massicano AVF, Gadhia D, McCarthy KA, Queern S, et al. Radiolabeled cationic peptides for targeted imaging of infection. Contrast Media Mol Imaging. (2019) 2019:3149249. doi: 10.1155/2019/3149249

38. Chopra S, Singh B, Koul A, Mishra AK, Robu S, Kaur A, et al. Radiosynthesis and pre-clinical evaluation of $\left[{ }^{68} \mathrm{Ga}\right]$ labeled antimicrobial peptide fragment GF-17 as a potential infection imaging PET radiotracer. Appl Radiat Isot. (2019) 149:9-21. doi: 10.1016/j.apradiso.2019.04.008

39. Weinstein EA, Ordonez AA, DeMarco VP, Murawski AM, Pokkali S, MacDonald EM, et al. Imaging Enterobacteriaceae infection in vivo with $18 \mathrm{~F}$ fluorodeoxysorbitol positron emission tomography. Sci Transl Med. (2014) 6:259ra146. doi: 10.1126/scitranslmed.3009815

40. Namavari M, Gowrishankar G, Hoehne A, Jouannot E, Gambhir SS. Synthesis of $\left[{ }^{18} \mathrm{~F}\right]$-labelled maltose derivatives as PET tracers for imaging bacterial infection. Mol Imaging Biol. (2015) 17:168-76. doi: 10.1007/s11307-014-0793-5

41. Gowrishankar G, Hardy J, Wardak M, Namavari M, Reeves RE, Neofytou E, et al. Specific imaging of bacterial infection using 6-18F-fluoromaltotriose: a second-generation PET tracer targeting the maltodextrin transporter in bacteria. J Nucl Med. (2017) 58:1679-84. doi: 10.2967/jnumed.117.191452

42. Shukla J, Arora G, Kotwal PP, Kumar R, Malhotra A, Bandopadhyaya GP. Radiolabeled oligosaccharides nanoprobes for infection imaging. Hell J Nucl Med. (2010) 13:218-23.

43. Pickett JE, Thompson JM, Sadowska A, Tkaczyk C, Sellman BR, Minola A, et al. Molecularly specific detection of bacterial lipoteichoic acid for diagnosis of prosthetic joint infection of the bone. Bone Res. (2018) 6:13. doi: 10.1038/s41413-018-0014-y

44. Foss CA, Kulik L, Ordonez AA, Jain SK, Michael Holers V, Thurman $\mathrm{JM}$, et al. SPECT/CT imaging of Mycobacterium tuberculosis infection with [(125)I]anti-C3d mAb. Mol Imaging Biol. (2019) 21:473-81. doi: 10.1007/s11307-018-1228-5

45. Thornton CR. Detection of the 'Big Five' mold killers of humans: Aspergillus, Fusarium, Lomentospora, Scedosporium and Mucormycetes. Adv Appl Microbiol. (2020) 110:1-61. doi: 10.1016/bs.aambs.2019.10.003

46. Page L, Ullmann AJ, Schadt F, Wurster S, Samnick S. In Vitro evaluation of radiolabeled amphotericin $\mathrm{B}$ for molecular imaging of mold infections. Antimicrob Agents Chemother. (2020) 64:e02377-19. doi: 10.1128/AAC.02377-19

47. Haas H, Petrik M, Decristoforo C. An iron-mimicking, Trojan horse-entering fungi-has the time come for molecular imaging of fungal infections? PLoS Pathog. (2015) 11:e1004568. doi: 10.1371/journal.ppat.1004568

48. Petrik M, Haas H, Laverman P, Schrettl M, Franssen GM, Blatzer M, et al. ${ }^{68} \mathrm{Ga}$-triacetylfusarinine $\mathrm{C}$ and ${ }^{68} \mathrm{Ga}$-ferrioxamine $\mathrm{E}$ for Aspergillus infection imaging: uptake specificity in various microorganisms. Mol Imaging Biol. (2014) 16:102-8. doi: 10.1007/s11307-013-0654-7

49. Davies G, Rolle AM, Maurer A, Spycher PR, Schillinger C, Solouk-Saran D, et al. Towards translational immunoPET/MR imaging of invasive pulmonary aspergillosis: the humanised monoclonal antibody JF5 detects aspergillus lung infections in vivo. Theranostics. (2017) 7:3398-414. doi: 10.7150/thno.20919

50. Henneberg S, Hasenberg A, Maurer A, Neumann F, Bornemann L, GonzalezMenendez I, et al. Antibody-guided in vivo imaging of Aspergillus fumigatus lung infections during antifungal azole treatment. Nat Commun. (2021) 12:1707. doi: 10.1038/s41467-021-21965-Z

51. Woodham AW, Zeigler SH, Zeyang EL, Kolifrath SC, Cheloha RW, Rashidian $\mathrm{M}$, et al. In vivo detection of antigen-specific CD8(+) $\mathrm{T}$ cells by immuno-positron emission tomography. Nat Methods. (2020) 17:102532. doi: 10.1038/s41592-020-0934-5

52. Song J, Cai Z, White AG, Jin T, Wang X, Kadayakkara D, et al. Visualization and quantification of simian immunodeficiency virus-infected cells using non-invasive molecular imaging. J Gen Virol. (2015) 96:313142. doi: 10.1099/jgv.0.000245 
53. Santangelo PJ, Rogers KA, Zurla C, Blanchard EL, Gumber S, Strait K, et al. Whole-body immunoPET reveals active SIV dynamics in viremic and antiretroviral therapy-treated macaques. Nat Methods. (2015) 12:42732. doi: 10.1038/nmeth.3320

54. Tsukrov D, McFarren A, Morgenstern A, Bruchertseifer F, Dolce E, Gorny $\mathrm{MK}$, et al. Combination of antiretroviral drugs and radioimmunotherapy specifically kills infected cells from HIV-infected individuals. Front Med. (2016) 3:41. doi: 10.3389/fmed.2016.00041

55. Rodríguez-Alfonso B, Ruiz Solís S, Silva-Hernández L, Pintos Pascual I, Aguado Ibáñez S, Salas Antón C. (18)F-FDG-PET/CT in SARS-CoV-2 infection and its sequelae. Rev Esp Med Nucl Imagen Mol. (2021) 40:299309. doi: 10.1016/j.remnie.2021.07.005

56. Casali M, Lauri C, Altini C, Bertagna F, Cassarino G, Cistaro A, et al. State of the art of (18)F-FDG PET/CT application in inflammation and infection: a guide for image acquisition and interpretation. Clin Transl Imaging. (2021) 10:1-41. doi: 10.1007/s40336-021-00445-w

57. Das JP, Yeh R, Schöder H. Clinical utility of perfusion (Q)-single-photon emission computed tomography (SPECT)/CT for diagnosing pulmonary embolus (PE) in COVID-19 patients with a moderate to high pretest probability of PE. Eur J Nucl Med Mol Imaging. (2021) 7949. doi: 10.1007/s00259-020-05043-y
58. Dadachova E, Berman JW. Non-invasive nuclear imaging for localization of viral reservoirs. Nat Methods. (2015) 12:399-400. doi: 10.1038/nmet h. 3373

Conflict of Interest: The authors declare that the research was conducted in the absence of any commercial or financial relationships that could be construed as a potential conflict of interest.

Publisher's Note: All claims expressed in this article are solely those of the authors and do not necessarily represent those of their affiliated organizations, or those of the publisher, the editors and the reviewers. Any product that may be evaluated in this article, or claim that may be made by its manufacturer, is not guaranteed or endorsed by the publisher.

Copyright (C) 2022 Dadachova and Rangel. This is an open-access article distributed under the terms of the Creative Commons Attribution License (CC BY). The use, distribution or reproduction in other forums is permitted, provided the original author(s) and the copyright owner(s) are credited and that the original publication in this journal is cited, in accordance with accepted academic practice. No use, distribution or reproduction is permitted which does not comply with these terms. 